\title{
Cardiac Valve Annulus Diameters in Extremely Preterm Infants: A Cross-Sectional Echocardiographic Study
}

\author{
Allard E. van Ark ${ }^{a} \quad$ Mirella C. Molenschot ${ }^{a} \quad$ Maria H. Wesseling ${ }^{a}$ \\ Willem B. de Vries ${ }^{b}$ Jan L.M. Strengers ${ }^{a}$ Arthur Adams ${ }^{c}$ \\ Johannes M.P.J. Breur ${ }^{a}$ \\ a Department of Pediatric Cardiology, Wilhelmina Children's Hospital, University Medical Center Utrecht, Utrecht, \\ The Netherlands; ${ }^{b}$ Department of Neonatology, Wilhelmina Children's Hospital, University Medical Center Utrecht, \\ Utrecht, The Netherlands; ' Department of Radiology and Nuclear Medicine, University Medical Center Utrecht, \\ Utrecht, The Netherlands
}

\section{Keywords}

Echocardiography · Reference values · Cardiac valves ·

Extremely preterm infants · Low birth weight

\begin{abstract}
Background: With the increasing incidence of births of very preterm very-low-birth-weight infants, there is a demand for echocardiographic reference values of cardiac dimensions. Objectives: The aim of this study was to provide reference values of cardiac valve annulus diameters in a cohort of extremely preterm very-low-birth-weight neonates and to correlate these with patient characteristics. Methods: Valve diameters of 376 infants of $<32$ weeks' gestation and with a birth weight of $\leq 2,000 \mathrm{~g}$ were measured using 2-dimensional echocardiography. Correlations between valve diameters and patient characteristics (birth length/weight, body surface area, gestational age, and sex) were assessed. Birth weight was used to establish linear regression models. Interand intraobserver agreement was assessed through intraclass correlation coefficient (ICC) analysis. Results: Substantial variability was found (aortic valve mean [standard devia-
\end{abstract}

tion; range]: $5.0 \mathrm{~mm}$ [0.6; 3.7-6.5]; pulmonic valve: $5.8 \mathrm{~mm}$ [0.8; 3.4-7.9]; mitral valve: $8.0 \mathrm{~mm}$ [1.0; 5.5-10.5]; tricuspid valve: $7.6 \mathrm{~mm}[1.2 ; 4.9-10.6])$. There was a moderate correlation between birth weight and valve diameter $\left(R^{2}\right.$ aortic valve: 0.36 ; pulmonic valve: 0.20 ; mitral valve: 0.24 ; tricuspid valve: 0.24 ). Adequate intraobserver (ICC range $0.74-0.91$ ) and interobserver agreement (ICC range 0.77-0.89) was found. Conclusions: Our study provides ready-to-use reference values for cardiac valve annulus diameters for extremely preterm infants.

(c) 2018 The Author(s)
Published by S. Karger AG, Basel

\section{Introduction}

Over the last decades, the incidence of very preterm low-weight births has increased due to an increase in multiple births, improvement of quality and availability

Allard E. van Ark and Mirella C. Molenschot contributed equally to this work.

\begin{tabular}{ll}
\hline KARGER & $\begin{array}{l}\text { @ } 2018 \text { The Author(s) } \\
\text { Published by S. Karger AG, Basel Openger }\end{array}$ \\
E-Mail karger@karger.com & This article is licensed under the Creative Commons Attribution- \\
www.karger.com/neo & $\begin{array}{l}\text { NonCommercial-NoDerivatives 4.0 International License (CC BY- } \\
\text { NC-ND) (http://www.karger.com/Services/OpenAccessLicense). } \\
\text { Usage and distribution for commercial purposes as well as any dis- } \\
\text { tribution of modified material requires written permission. }\end{array}$
\end{tabular}

Mirella C. Molenschot, MD

Department of Pediatric Cardiology, Wilhelmina Children's Hospital

University Medical Center Utrecht, PO Box 85090

NL-3584 EA Utrecht (The Netherlands)

E-Mail m.m.c.molenschot@ umcutrecht.nl 
Table 1. Overview of previous studies on cardiac valve annulus diameters in neonates

\begin{tabular}{|c|c|c|c|c|c|c|c|c|c|c|c|c|}
\hline $\begin{array}{l}\text { First author, } \\
\text { year [ref.] }\end{array}$ & $n$ & Age & \multicolumn{4}{|c|}{ Valves included } & \multicolumn{6}{|c|}{ Independent variable } \\
\hline Cantinotti, 2017 [17] & 1,151 & $0-17 y$ & $\mathrm{x}$ & $\mathrm{x}$ & $\mathrm{x}$ & $\mathrm{x}$ & & & $\mathrm{x}$ & & & \\
\hline Cantinotti, 2014 [16] & 443 & $0-36 \mathrm{~m}$ & $\mathrm{x}$ & $\mathrm{x}$ & $\mathrm{x}$ & $\mathrm{x}$ & & & $\mathrm{x}$ & & & \\
\hline Daubeney, 1999 [12] & 127 & $0-17 y$ & $\mathrm{x}$ & $\mathrm{x}$ & $\mathrm{x}$ & $\mathrm{x}$ & & & $\mathrm{x}$ & & & \\
\hline King, 1985 [8] & 103 & $0-15 y$ & & & $\mathrm{x}$ & $\mathrm{x}$ & $\mathrm{x}$ & $\mathrm{x}$ & $\mathrm{x}$ & $\mathrm{x}$ & & \\
\hline Pettersen, 2008 [15] & 782 & $0-18 \mathrm{y}$ & $\mathrm{x}$ & $\mathrm{x}$ & $\mathrm{x}$ & $\mathrm{x}$ & & & $\mathrm{x}$ & & & \\
\hline Skelton, 1998 [11] & 79 & $<34$ wks GA & $\mathrm{x}$ & & & & $\mathrm{x}$ & & & & $\mathrm{x}$ & \\
\hline Snider, 1984 [7] & 110 & $0-18 y$ & $\mathrm{x}$ & $\mathrm{x}$ & & & $\mathrm{x}$ & $\mathrm{x}$ & $\mathrm{x}$ & $\mathrm{x}$ & & \\
\hline Solinger, 1973 [6] & 240 & $0-8 \mathrm{~d}$ & & & $\mathrm{x}$ & $\mathrm{x}$ & $\mathrm{x}$ & & & & & \\
\hline Tacy, $1995[10]$ & 70 & $0-10 \mathrm{~d}$ & $\mathrm{x}$ & $\mathrm{x}$ & $\mathrm{x}$ & $\mathrm{x}$ & $\mathrm{x}$ & & & & & \\
\hline
\end{tabular}

$\mathrm{AV}$, aortic valve; PV, pulmonary valve; MV, mitral valve; tricuspid valve; BW, birth weight; BL, birth length; BSA, body surface area; HC, head circumference; GA, gestational age; MB, multiple birth; wks, weeks; y, years; m, months; d, days.

of neonatal intensive care, and lower viability thresholds [1]. With this increase, the need for echocardiographic reference values increases equally. Newborns with congenital heart disease have a two-fold higher risk of (spontaneous) preterm birth than the general population [2]. Low birth weight (BW) has been established as a factor associated with the development of congenital heart disease [3].

Echocardiography is the principal imaging modality for the detection and management of congenital heart disease $[4,5]$. Echocardiographic reference values for cardiac valve dimensions have been established for neonates using both $\mathrm{M}$-mode and 2-dimensional echocardiography. However, specific data on cardiac valve dimensions in preterm neonates are scarce [4]. Reference values have been established in term neonates or mixed populations of term and preterm neonates, often as a subgroup within a population spanning a broader range of childhood years [6-17] (Table 1). No study specifically aimed at preterm neonates, except for Skelton et al. [11] and Abushaban et al. [18].

The aim of this study was to provide echocardiographic reference values for cardiac valve annulus diameters in a large cohort of extremely preterm low-BW neonates. We correlated these values with easy-to-obtain clinical characteristics (such as BW, birth length, and body surface area $[\mathrm{BSA}]$ ) in order to assess the ability to measure biological variability.

Cardiac Valve Diameters in Preterm Infants

\section{Methods}

\section{Study Population}

Data for this cross-sectional study were derived from the Ductus study cohort, a study that was designed to investigate the hemodynamic significance of patent ductus arteriosus (PDA) [19, 20]. Data were collected at the neonatal intensive care unit of the Wilhelmina Children's Hospital, a tertiary pediatric hospital in Utrecht, The Netherlands. From September 2008 until October 2010, infants born alive between 24 weeks (the viability threshold in the Netherlands) and 32 weeks of gestation were included. Study population characteristics have been described elsewhere [21]. The presence of a PDA or patent foramen ovale (PFO) was not considered an exclusion criterion. Ethical approval was obtained from the local medical ethics board.

\section{Echocardiographic Examination and Valve Measurements}

Echocardiographic images were acquired through routine echocardiographic examination with special focus on the PDA on the second, fourth, and sixth day of life. All examinations were performed by pediatric cardiologists or experienced echocardiography technicians using a GE Vivid I system (GE Healthcare, Little Chalfont, UK) using 7- or 10-MHz transducers. Dynamic images were stored on GE EchoPac version 112 (GE Healthcare) for offline analysis. Cardiac valve annulus diameters were measured by 2 investigators (A.E.A. and M.H.W.) after training by a senior pediatric cardiologist (M.C.M.) in accordance with guidelines on quantification methods of pediatric echocardiograms by the American Society of Echocardiography [5]. Valve annuli were measured from hinge point to hinge point at maximal expansion. The aortic valve was measured in the parasternal long axis view during peak systole. Mitral and tricuspid valves were measured in the apical 4-chamber view during peak diastole. The pulmonary 


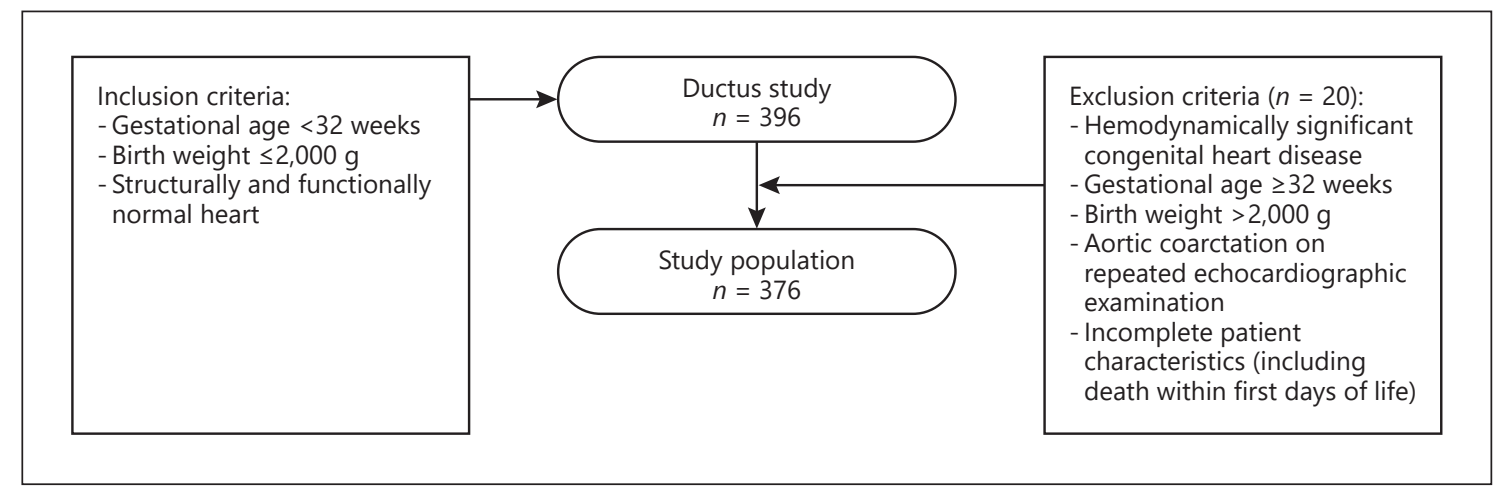

Fig. 1. Study population flowchart of patients in the Ductus study cohort.

Table 2. Study population characteristics of evaluated patients in the Ductus study cohort

\begin{tabular}{lclll}
\hline & $n$ & Range & Mean (SD) & Median (IQR) \\
\hline Male & $108(47.9 \%)$ & & & \\
$\mathrm{HC}, \mathrm{cm}(n=373)$ & & $19.5-41.0$ & $26.8(2.4)$ & $27.0(25.5-28.0)$ \\
$\mathrm{BL}, \mathrm{cm}(n=343)$ & & $26.0-45.0$ & $37.8(3.4)$ & $38.0(36.0-40.0)$ \\
$\mathrm{BSA}, \mathrm{m}^{2}(n=341)$ & & $0.07-0.16$ & $0.12(0.02)$ & $0.12(0.10-0.13)$ \\
$\mathrm{BW}, \mathrm{kg}(n=376)$ & $0.53-2.00$ & $1.27(0.34)$ & $1.25(1.00-1.52)$ \\
GA, weeks $(n=376)$ & $116(30.9 \%)$ & $24.3-31.9$ & $29.4(1.8)$ & $29.9(28.1-30.9)$ \\
Multiple birth $\quad 110$ & & & \\
$\quad$ As part of twins & & & & \\
\multicolumn{1}{l}{ As part of triplets } & 6 & & & \\
\hline
\end{tabular}

SD, standard deviation; IQR, interquartile range; HC, head circumference; BL, birth length; BSA, body surface area; BW, birth weight; GA, gestational age.

valve was measured in the parasternal short axis view during peak systole. For each patient, the three echocardiographic examinations were analyzed image by image. Wherever multiple goodquality images for a single valve were available, the image of highest quality by judgment of the individual investigator was selected for the measurement.

\section{Intraobserver and Interobserver Variability}

In order to assess the individual reproducibility of measurements in offline analysis, intraobserver variability was examined using separate measurements of different images of the same valve in each patient. Interobserver variability was examined to determine reproducibility of measurements in offline analysis between researchers, using a limited set of 50 random control measurements in offline analysis. The image of highest quality by judgment of the individual investigator was selected for control measurements.

\section{Statistical Analysis}

Descriptive statistics were used to assess population and cardiac valve characteristics. Pearson $R$ correlation was used to assess the degree of correlation between cardiac valve annulus diameter and clinical characteristics (BW, birth length, BSA, head circumference and gestational age). The Haycock formula was used to calculate BSA, as this formula provides the best estimate for BSA, especially in the lower ranges $[16,22,23]$. In comparison to BSA and birth length, BW was considered the most objectively measurable clinical variable and was, therefore, used as an independent variable for regression analysis. Univariate linear regression was applied to derive regression equations for each valve, using BW as the independent variable, providing the intercept and slope $(\beta)$ of the regression line, the $95 \%$ confidence interval for $\beta$, and the calculated $z$-score formula for each valve. One-way random intraclass coefficient analysis (single measures where people effects are random) was used to assess intra- and interobserver variability.

Statistical analysis was performed using IBM SPSS 21.0 (International Business Machines Corporation, Armonk, NY, USA). $p$ values $<0.05$ were considered statistically significant.

\section{Results}

The Ductus study population consisted of 396 neonates. Four patients were excluded due to incomplete patient characteristics, and three patients died within the 


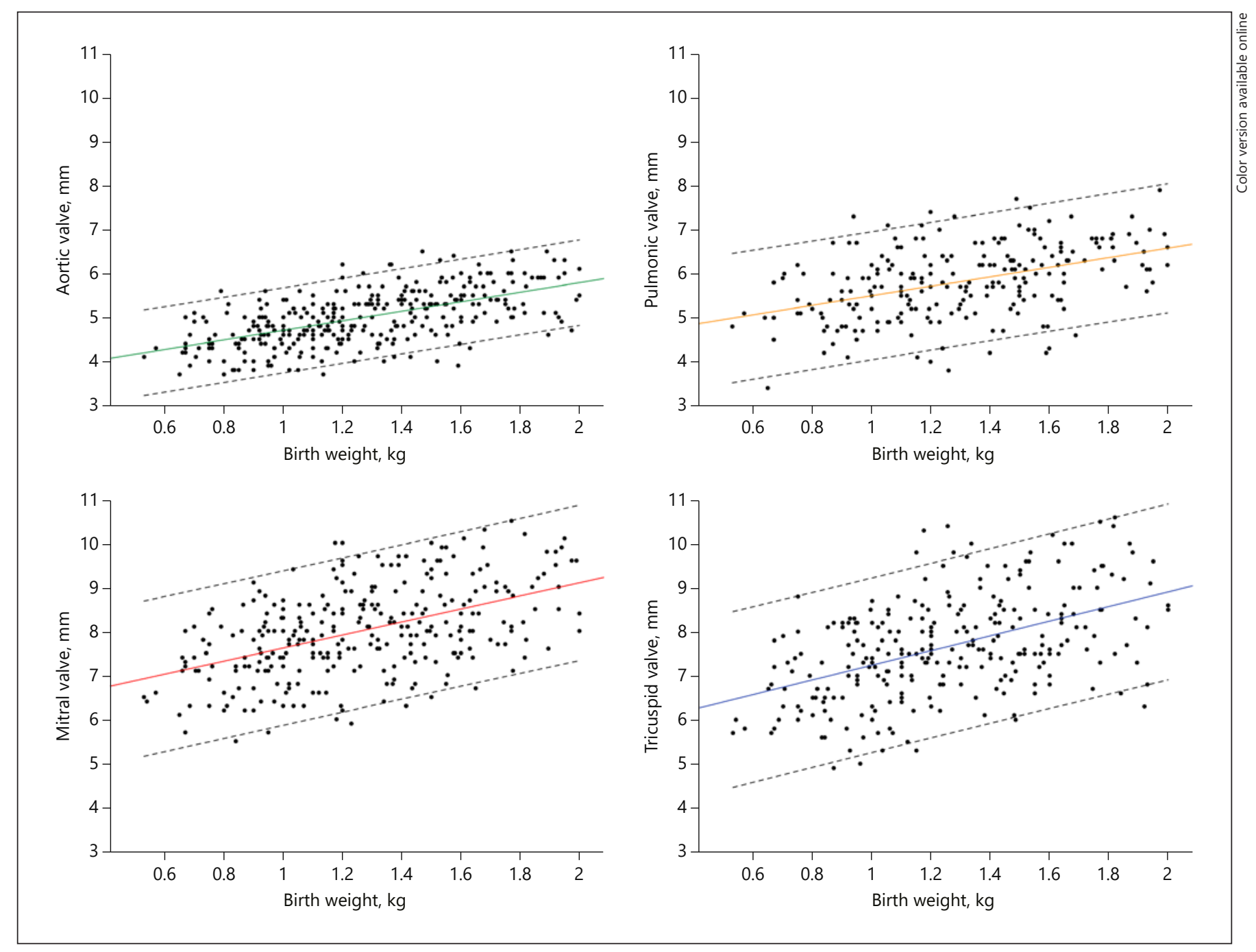

Fig. 2. Scatterplots for aortic, pulmonic, mitral, and tricuspid valve annulus diameter by birth weight of patients in the Ductus study cohort $(n=376)$. The central line represents the linear regression equation, the outer lines represent the $95 \%$ confidence interval of the regression line.

first days of life. Twelve infants did not meet the gestational age or BW requirements. One patient was diagnosed with coarctation of the aorta. Exclusion of the described cases left 376 infants for the analysis (Fig. 1).

Median BW was $1.25 \mathrm{~kg}$ (interquartile range [IQR] 1.00-1.52; range $0.53-2.00$ ), and median gestational age was 29.9 weeks (IQR 28.1-30.9; range 24.3-31.9). Of all subjects, 116 (30.9\%) were part of a multiple birth, including two triplets (Table 2).

Online supplementary Figure 1 (for all online suppl. material, see www.karger.com/doi/10.1159/000488387) shows an example of offline measurement of annulus di- ameter for each valve. Substantial variability in annulus diameter was found between subjects for each of the valves (Table 2). Pearson $R$ yielded equal correlations for BW ( $R$ coefficient range $0.47-0.60)$ and BSA ( $R$ coefficient range $0.48-0.61$ ) with each of the valves (online suppl. Table 1). Linear regression $\beta$ coefficients ranged from 1.08 to $1.67 \mathrm{~mm} / \mathrm{kg}$ body weight (Table 3 ). Scatter plots show the variability in annulus diameter across the BW range for each valve (Fig. 2).

Intraobserver intraclass correlation coefficient (ICC) ranged from 0.74 to 0.91 and interobserver ICC ranged from 0.77 to 0.89 (Table 4 ). 
Table 3. Cardiac valve characteristics and coefficients for regression equations relating echoardiographic measurements with birth weight

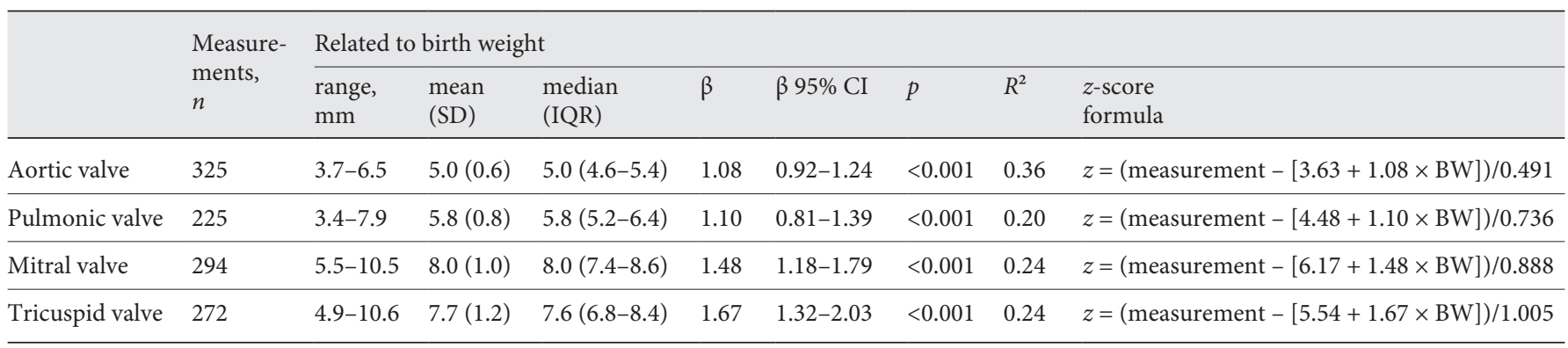

SD, standard deviation; IQR, interquartile range; $\beta$, beta coefficient; $95 \% \mathrm{CI}, 95 \%$ confidence interval for $\beta ; R^{2}$, goodness-of-fit statistic; BW, body weight; $z=($ measurement $-[$ intercept $+\beta \times \mathrm{BW}]) /$ standard error of the estimate $(\mathrm{BW}[\mathrm{kg}]$, valve diameter $[\mathrm{mm}])$.

Table 4. ICCs of intra- and interobserver variability

\begin{tabular}{|c|c|c|c|c|c|c|}
\hline & \multicolumn{3}{|c|}{ Intraobserver variability } & \multicolumn{3}{|c|}{ Interobserver variability } \\
\hline & $n$ & ICC & $95 \% \mathrm{CI}$ & $n$ & ICC & $95 \% \mathrm{CI}$ \\
\hline Aortic valve & 187 & 0.90 & $0.87-0.92$ & 89 & 0.89 & $0.83-0.92$ \\
\hline Pulmonic valve & 98 & 0.74 & $0.64-0.82$ & 58 & 0.88 & $0.80-0.92$ \\
\hline Mitral valve & 158 & 0.91 & $0.88-0.93$ & 93 & 0.77 & $0.67-0.84$ \\
\hline Tricuspid valve & 131 & 0.89 & $0.85-0.92$ & 84 & 0.87 & $0.81-0.91$ \\
\hline
\end{tabular}

One-way random effects model where people effects are random. ICC, intraclass correlation coefficient; 95\% CI, 95\% confidence interval for the ICC.

\section{Discussion}

In this study, we established reference values of cardiac valve annulus diameters for preterm low-BW neonates. To our knowledge, this is the largest study to specifically describe cardiac valve dimensions of extremely preterm neonates. In our study, BW was used as the independent variable for linear regression analysis. In addition to being an easy-to-obtain clinical parameter, its correlation with the valves proved to be comparable to BSA in our neonatal population.

Our results show a moderate relationship between BW and each valve ( $R^{2}$ range $\left.0.20-0.36\right)$, which can be explained in various ways. First, there is apparent biological variation in annulus diameters among patients that remains even after correction for clinical variables. Second, the accuracy of offline analysis should be considered. A limited image resolution with measurements in (sub-) millimeter dimensions, measurements performed by different echocardiographers, the method of routine echocardiographic examinations among individual echocar- diographers, the specific types of echocardiographic equipment, imaging transducers used, and measurement variability can all have influenced the accuracy of the offline image analysis and could subsequently have contributed to the substantial variance. Furthermore, the images on which the data of our study are based were initially acquired for assessment of PDA closure. Therefore, the acquisition of these images was not specifically aimed at measuring cardiac valves.

In a study of 268 preterm infants, Abushaban et al. [18] examined the correlation between cardiac valve annulus diameters and both gestational age and weight. In contrast to our study, the authors did not perform regression analysis to provide $z$-score equations. The correlation between the aortic valve annulus diameter and weight was comparable to the results of our study ( 0.57 vs. 0.60$)$, whereas the correlation between pulmonary, mitral, and tricuspid valve was somewhat stronger than in our study ( 0.59 vs. $0.48,0.67$ vs. 0.49 , and 0.68 vs. 0.47 ). They found higher mean valve diameters at $0-6$ days of life, which is probably due to inclusion of newborns with a BW of $>2,000 \mathrm{~g}$. 
One study examined the linear relationship between cardiac valve annulus diameters and BW in neonates. Tacy et al. [10] established linear models for each of the cardiac valves with $R^{2}$ values ranging from 0.59 to 0.78 for the valves, supporting the existence of a linear relationship between BW and cardiac valve annulus diameter for neonates. Regression equations and standard errors of the estimate were comparable to our findings for the aortic and pulmonic valves but differed for the mitral and tricuspid valves. The latter could possibly be attributed to the broader BW interval in their study (500-4,000 g). The difference in goodness of fit in comparison to our study could at least partly be attributed to a modification of the BW variable to guarantee an equal distribution across the range of weights.

In previous studies that included neonates, nonlinear models correlating cardiac dimensions with BSA were investigated in study populations with broader age intervals [8-11, 14-16]. Consensus has been reached on the use of BSA as the independent variable in establishing pediatric echocardiographic reference values in general [5]. For neonates, however, it has been suggested that an increase in weight does not result in a concomitant increase in BSA $[10,24]$. In our study, correlation analysis (online suppl. Table 1) showed that BW and BSA correlated equally with each of the valves, supporting the use of BW as an independent variable.

The results of the interobserver and intraobserver variability analysis show good reproducibility of measurements by the same observer (ICC range 0.74-0.91) as well as between observers (ICC range 0.77-0.89). Previous studies reported reproducibility of measurements in various ways, with good reproducibility for each valve in all studies $[9,10,16]$.

Our study has several limitations. Its main limitation concerns its retrospective, cross-sectional design, which does not allow an evaluation of the diagnostic or prognostic value of the reference values through (long-term) follow-up. Also, due to the retrospective design, we could not control for PDA or PFO. We, therefore, considered a PDA or PFO on echocardiographic examination to be physiological, in accordance with previous studies [15, 16]. In a similar way, we were not able to adjust for ethnicity, which has been suggested as a possible confounder [4]. We could not control for gender due to an unbalanced distribution of missing valve data among the sexes $[4,13]$. Finally, measurement of the pulmonary and mitral valves was affected by poor lateral wall delineation in the parasternal short axis view and the apical 4-chamber view, respectively, which has been reported in previous studies as well $[9,16]$. The missing values in our data can

Cardiac Valve Diameters in Preterm Infants be attributed to large extent to poor lateral wall visibility. Poor lateral wall visibility could also account for the lower intraobserver and interobserver ICC values for the pulmonary and mitral valves, respectively. Missing values of the aortic valve were most often due to unavailability of images rather than poor image quality.

Regarding future research, we suggest that these reference values should be validated for preterm infants with congenital heart disease. Plymale et al. [25] evaluated cardiac valve dimensions in 73 infants with aortic arch hypoplasia and small left heart structures, with a median BW of $3.1 \mathrm{~kg}$ and a median gestational age of 38 weeks. Median postoperative diameters for the aortic and mitral valves were comparable to our study (5.0-5.3 vs. $5.0 \mathrm{~mm}$; $7.3-8.0$ vs. $8.0 \mathrm{~mm}$ ), corresponding with median $z$-scores of -2.0 and -3.0 , respectively.

Another suggestion for future research would be the reproducibility of preterm neonatal measurements in fetal echocardiography. $z$-scores of cardiac dimensions in fetal echocardiography allow for a more precise early evaluation of complex congenital heart defects, contributing to prenatal diagnosis of critical congenital heart disease [26]. This could reduce the risk of death from cardiovascular compromise prior to planned neonatal cardiac surgery [27]. In 130 fetuses (15-39 weeks of gestation), Schneider et al. [28] established reference values for 17 cardiac dimensions. To compute $z$-scores, univariate regression analysis with logarithmic transformation was applied, using femur length, biparietal diameter, and gestational age as independent variables. Similarly, Lee et al. [29] computed $z$-scores of 5 cardiac dimensions (including the aortic and pulmonic valves) in a population of 2,735 fetuses through linear regression, using femoral length, menstrual age, and biparietal diameter as predictors. In contrast to Schneider et al. [28], they found that simple linear regression models best described their data. We suggest that a follow-up study, comparing cardiac (valve) dimensions between fetuses in the third trimester of intrauterine development and extremely premature neonates of equal gestational age, could clarify to what extent reference values for extremely preterm newborns could be extrapolated to fetal echocardiography.

Finally, we suggest that specific nomograms for preterm neonates should also be derived for pulse wave and tissue Doppler imaging of cardiac valve dimensions [30]. In conclusion, we have provided ready-to-use reference values for cardiac valve annulus diameters specifically for extremely preterm infants, assessing the ability to demonstrate biological variability in a larger population, with good reproducibility of measurements. 


\section{Disclosure Statement}

\section{References}

1 Blencowe $\mathrm{H}$, Cousens S, Oestergaard MZ, Chou D, Moller AB, Narwal R, Adler A, Vera Garcia C, Rohde S, Say L, Lawn JE: National, regional, and worldwide estimates of preterm birth rates in the year 2010 with time trends since 1990 for selected countries: a systematic analysis and implications. Lancet 2012;379: 2162-2172.

2 Laas E, Lelong N, Thieulin AC, Houyel L, Bonnet D, Ancel PY, Kayem G, Goffinet F, Khoshnood B: Preterm birth and congenital heart defects: a population-based study. Pediatrics 2012;130:e829-e837.

3 Rosenthal GL, Wilson PD, Permutt T, Boughman JA, Ferencz C: Birth weight and cardiovascular malformations: a population-based study. The Baltimore-Washington Infant Study. Am J Epidemiol 1991;133:1273-1281.

4 Cantinotti M, Scalese M, Molinaro S, Murzi B, Passino C: Limitations of current echocardiographic nomograms for left ventricular, valvular, and arterial dimensions in children: a critical review. J Am Soc Echocardiogr 2012; 25:142-152.

5 Lopez L, Colan SD, Frommelt PC, Ensing GJ, Kendall K, Younoszai AK, Lai WW, Geva T: Recommendations for quantification methods during the performance of a pediatric echocardiogram: a report from the Pediatric Measurements Writing Group of the American Society of Echocardiography Pediatric and Congenital Heart Disease Council. J Am Soc Echocardiogr 2010;23:465-495; quiz 576-467.

6 Solinger R, Elbl F, Minhas K: Echocardiography in the normal neonate. Circulation 1973 47:108-118.

7 Snider AR, Enderlein MA, Teitel DF, Juster RP: Two-dimensional echocardiographic determination of aortic and pulmonary artery sizes from infancy to adulthood in normal subjects. Am J Cardiol 1984;53:218-224.

8 King DH, Smith EO, Huhta JC, Gutgesell HP: Mitral and tricuspid valve annular diameter in normal children determined by two-dimensional echocardiography. Am J Cardiol 1985;55:787-789.

9 Hanseus K, Bjorkhem G, Lundstrom NR: Dimensions of cardiac chambers and great vessels by cross-sectional echocardiography in infants and children. Pediatr Cardiol 1988;9: 7-15.

10 Tacy TA, Vermilion RP, Ludomirsky A: Range of normal valve annulus size in neonates. Am J Cardiol 1995;75:541-543.
We declare that we have no conflicts of interests. This research did not receive any specific grant from funding agencies in the public, commercial, or not-for-profit sectors.
11 Skelton R, Gill AB, Parsons JM: Reference ranges for cardiac dimensions and blood flow velocity in preterm infants. Heart 1998;80: 281-285.

12 Daubeney PE, Blackstone EH, Weintraub RG, Slavik Z, Scanlon J, Webber SA: Relationship of the dimension of cardiac structures to body size: an echocardiographic study in normal infants and children. Cardiol Young 1999;9: 402-410.

13 Zilberman MV, Khoury PR, Kimball RT: Two-dimensional echocardiographic valve measurements in healthy children: genderspecific differences. Pediatr Cardiol 2005;26: 356-360.

14 Kaldararova M, Balazova E, Tittel P, Stankovicova I, Brucknerova I, Masura J: Echocardiographic measurements of the aorta in normal children and young adults. Bratisl Lek Listy 2007;108:437-441.

15 Pettersen MD, Du W, Skeens ME, Humes RA: Regression equations for calculation of $\mathrm{z}$ scores of cardiac structures in a large cohort of healthy infants, children, and adolescents: an echocardiographic study. J Am Soc Echocardiogr 2008;21:922-934.

16 Cantinotti M, Scalese M, Murzi B, Assanta N, Spadoni I, Festa P, De Lucia V, Crocetti M, Marotta M, Molinaro S, Lopez L, Iervasi G: Echocardiographic nomograms for ventricular, valvular and arterial dimensions in Caucasian children with a special focus on neonates, infants and toddlers. J Am Soc Echocardiogr 2014;27:179-191.

17 Cantinotti M, Giordano R, Scalese M, Murzi B, Assanta N, Spadoni I, Maura C, Marco M, Molinaro S, Kutty S, Iervasi G: Nomograms for two-dimensional echocardiography derived valvular and arterial dimensions in Caucasian children. J Cardiol 2017;69:208-215.

18 Abushaban L, Vel MT, Rathinasamy J, Sharma PN: Normal reference ranges for cardiac valve annulus in preterm infants. Pediatr Cardiol 2016;37:112-119.

19 Dix L, Molenschot M, Breur J, de Vries W, Vijlbrief D, Groenendaal F, van Bel F, Lemmers P: Cerebral oxygenation and echocardiographic parameters in preterm neonates with a patent ductus arteriosus: an observational study. Arch Dis Child Fetal Neonatal Ed 2016;101: F520-F526.

20 Dix LM, Blok CA, Lemmers PM, van der Aa N, Molenschot MC, Vreman HJ, Krediet T, van Bel F: Early end-tidal carbon monoxide levels, patency of the ductus arteriosus and regional cerebral oxygenation in preterm infants. Neonatology 2014;105:161-165.
21 Dijkema EJ, Molenschot MC, Breur JM, de Vries WB, Slieker MG: Normative values of aortic arch structures in premature infants. J Am Soc Echocardiogr 2017;30:227-232.

22 Sluysmans T, Colan SD: Theoretical and empirical derivation of cardiovascular allometric relationships in children. J Appl Physiol 2005; 99:445-457.

23 Haycock GB, Schwartz GJ, Wisotsky DH Geometric method for measuring body surface area: a height-weight formula validated in infants, children, and adults. J Pediatr 1978; 93:62-66.

24 Kampmann C, Wiethoff CM, Wenzel A, Stolz G, Betancor M, Wippermann CF, Huth RG, Habermehl P, Knuf M, Emschermann T, Stopfkuchen H: Normal values of M mode echocardiographic measurements of more than 2,000 healthy infants and children in central Europe. Heart 2000;83:667-672.

25 Plymale JM, Frommelt PC, Nugent M, Simpson P, Tweddell JS, Shillingford AJ: The infant with aortic arch hypoplasia and small left heart structures: echocardiographic indices of mitral and aortic hypoplasia predicting successful biventricular repair. Pediatr Cardiol 2017;38:1296-1304.

26 Devore GR: The use of Z-scores in the analysis of fetal cardiac dimensions. Ultrasound $\mathrm{Ob}$ stet Gynecol 2005;26:596-598.

27 Holland BJ, Myers JA, Woods CR Jr: Prenatal diagnosis of critical congenital heart disease reduces risk of death from cardiovascular compromise prior to planned neonatal cardiac surgery: a meta-analysis. Ultrasound $\mathrm{Ob}$ stet Gynecol 2015;45:631-638.

28 Schneider C, McCrindle BW, Carvalho IS, Hornberger LK, McCarthy KP, Daubeney PE: Development of Z-scores for fetal cardiac dimensions from echocardiography. Ultrasound Obstet Gynecol 2005;26:599-605.

29 Lee W, Riggs T, Amula V, Tsimis M, Cutler $\mathrm{N}$, Bronsteen R, Comstock CH: Fetal echocardiography: $\mathrm{z}$-score reference ranges for a large patient population. Ultrasound Obstet Gynecol 2010;35:28-34.

30 Cantinotti M, Giordano R, Scalese M, Murzi B, Assanta N, Spadoni I, Crocetti M, Marotta M, Molinaro S, Kutty S, Iervasi G: Nomograms for mitral inflow Doppler and tissue Doppler velocities in Caucasian children. J Cardiol 2016;68:288-299. 